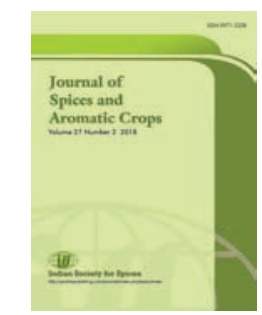

\title{
Comparative gene expression study between two turmeric (Curcuma longa L.) cultivars
}

\author{
D K Ayer*, K G Modha, V B Parekh, R K Patel, V Ramtekey \& A P Bhuriya \\ Department of Genetics and Plant Breeding, N. M. College of Agriculture, \\ Navsari Agricultural University, Navsari-396 450, Gujarat. \\ ${ }^{*}$ E-mail: dip_ayer@hotmail.com
}

Received 28 June 2018; Revised 03 September 2018; Accepted 25 October 2018

\begin{abstract}
Two turmeric (Curcuma longa L.) cultivars differing in curcumin content viz GNT-2 (4.6 \% curcumin) and NDH-98 (1.6\% curcumin) were selected for comparative gene expression study in association with total curcumin contents. Sampling was done at six months after planting in open field condition. Differential gene expression patterns were observed between two cultivars by reverse transcriptionquantitative real time polymerase chain reaction (RT-qPCR), and total curcumin contents were quantified using high performance liquid chromatography (HPLC). Low curcumin yielding cultivar, NDH-98, exhibited higher expression of DCS and CURS3 whereas lower expression of CURS1 and CURS2. However, opposite pattern was observed in a high curcumin yielding cultivar, GNT-2, where DCS and CURS3 expressions were lower but CURS1 and CURS2 expressions were higher. CURS3 showed similar expression between both cultivars. CURS1 and CURS2 expression patterns showed more closer association than DCS and CURS3 gene expression patterns with each other. Differential gene expression patterns could be predictively associated with differential curcuminoids concentrations in turmeric cultivars.
\end{abstract}

Keywords: curcumin, curcumin synthase, gene expression, turmeric

\section{Introduction}

Curcuma longa L. $(2 \mathrm{n}=3 \mathrm{x}=63)$, a rhizomatous, herbaceous and perennial plant belonging to the Zingiberaceae family, is a native to Southeast Asia and widely cultivated in the tropical and subtropical regions of the world (Sheeja et al. 2015). Turmeric has very long history of medicinal, culinary and religious use (Prasad \& Aggarwal 2011; Ravindran et al. 2007). Curcuma contains $3-5 \%$ curcuminoids with major portion of bioactive ingredient, curcumin (Agrawal \& Mishra 2010). Curcumin from this 'golden spice' crop is proven for its wide range of agricultural importance (Chan et al. 2014), pharmacological activities, cosmetic industrial value and cultural importance (Gupta et al. 2013; Krup et al. 2013). Curcumin, demethoxycurcumin and bisdemethoxycurcumin, also known as curcuminoids, are the most important bioactive 
constituents of turmeric (Esatbeyoglu et al. 2012; Sandur et al. 2007). At present, traditionally known curcumin has emerged as a modern biological regulator "curcuminoids". Agroclimatic and soil environmental variation are also influencing the curcumin synthase gene expression which is correlated with curcumin yield in turmeric cultivars (Sandeep et al. 2017). Novel gene identification, gene expression analysis and validations are possible with the advent of quantitative real-time polymerase chain reaction (qPCR) and RNA sequencing (RNA-Seq) methods (Li et al. 2015). Genomic and data mining-based studies in turmeric have identified major multiple curcumin synthase enzyme genes involved in curcuminoid biosynthesis pathway viz diketide-CoA synthase (DCS), curcumin synthase 1 (CURS1), curcumin synthase 2 (CURS2) and curcumin synthase 3 (CURS3) (Katsuyama et al. 2009a; Katsuyama et al. 2009b). Authors also reported that expression levels of the multiple curcumin synthases are capable of curcuminoid synthesis which might influence the composition of curcuminoids in different cultivars of turmeric. . This study was aimed to describe the differential gene expressions of multiple curcumin synthases in two different cultivars with different curcumin contents which might be useful to predict association of multiple curcumin synthases with different curcumin or curcuminoids concentrations in turmeric.

\section{Materials and methods}

\section{Handling experimental materials}

To prevent RNA degradation from RNases, disposable plastic wares, glass wares, metal wares, mortar and pestle were treated with DEPC water $(0.1 \%)$ overnight using Millipore (Merk) water and autoclaved for 20 minutes at $120^{\circ} \mathrm{C}$. The plastic wares were dry sterilized in laminar flow with partial treatment of UV light for 30 minutes to further ensure sterile-nuclease free condition. Two turmeric cultivars, GNT-2 (4.6\% curcumin, $28.7 \mathrm{t} \mathrm{ha}^{-1}$ rhizome yield), and NDH-98 (1.6\% curcumin, $33.5 \mathrm{t} \mathrm{ha}^{-1}$ rhizome yield) grown in open field condition in research field of Department of Genetics and Plant Breeding, NMCA, Navsari Agricultural University (NAU), Navsari, India were selected for the studies. Three biological samples per cultivar were randomly selected for RNA isolation from six months old plant at which all the aerial parts started senescing and curcumin synthesis is assumed to be stopped afterwards i.e. initial dormancy stage of rhizome. Rhizome fingers were excised from mother rhizome with sterile knife and washed, packed in to plastic vial along with identification number and immediately dipped in liquid nitrogen $\left(-196{ }^{\circ} \mathrm{C}\right)$ container before RNA isolation.

\section{RNA isolation and cDNA synthesis}

Total RNA was isolated using RNeasy® Plant Mini Kit (Qiagen, Germany) following the manufacturer's protocol. The integrity and size distribution of total RNA purified with RNeasy Kits was checked by $1.2 \%$ denaturing agarose gel electrophoresis and ethidium bromide staining visualizing two sharp bands of $28 \mathrm{~S}$ rRNA to $18 \mathrm{~S}$ rRNA in 2:1 ratio. The nanodrop results showed the acceptable purity of RNA isolated in each biological sample $\left(\mathrm{A}_{260} / \mathrm{A}_{280}\right.$ of 1.6 to 1.87 with nucleic acid concentration of 30-93 ng/ $\mu \mathrm{l}$ ). The isolated RNA was stored immediately at $-20^{\circ} \mathrm{C}$ in nuclease free water for further application. cDNA was synthesized by using Verso cDNA synthesis kit (Thermo Scientific, USA) following manufacturer's protocol.

\section{Primer screening through gradient PCR}

After cDNA synthesis, the samples were used for gradient PCR for each pair of the gene specific forward and reverse primers along with reference genes Actin, (Table 1) to find out their annealing temperature and size range of PCR products in gradient PCR thermocycler (Life Sciences instrument). The best annealing temperature of qPCR primers were found to be ranging from $58-60{ }^{\circ} \mathrm{C}$. Top Taq Master Kit (Qiagen, Germany) was used for gradient PCR following manufacturer's protocol.

\section{Quantitative real-time PCR ( $q P C R$ )}

cDNA samples were 10-fold diluted using molecular biology grade water before using as a template in qPCR reactions. The efficiency of the reaction after dilution was confirmed by taking $1 \mu \mathrm{L}$ cDNA template from each 10 -fold diluted sample for normal PCR in My Cycler PCR instrument (Bio-Rad Laboratories instrument) using Top Taq Master Mix (Qiagen, Germany) using manufacturer's protocol. $0.2 \mathrm{iM}$ each of 
Table 1. Gene specific primers used in standard PCR and qPCR assay

\begin{tabular}{|c|c|c|c|c|c|c|}
\hline Gene & Primer sequence $\left(5^{\prime}\right.$ to $\left.3^{\prime}\right)$ & $\begin{array}{l}\text { Primer } \\
\text { length }\end{array}$ & $\begin{array}{l}\text { Reference } \\
\text { sequence }\end{array}$ & $\begin{array}{l}\text { BLAST } \\
\text { product } \\
\text { size in } \\
\text { turmeric/ } \\
\text { NCBI }\end{array}$ & $\begin{array}{l}\text { Observed } \\
\text { size in } 2 \% \\
\text { agarose gel }\end{array}$ & References \\
\hline $\begin{array}{l}D C S \\
\text { (forward) }\end{array}$ & GTGCTGTTCATCCTGGACGAG & $21 b p$ & AB495006.1 & $90 \mathrm{bp}$ & $92-94 b p$ & $\begin{array}{l}\text { (Katsuyama } \\
\text { et al. 2009a) }\end{array}$ \\
\hline $\begin{array}{l}D C S \\
\text { (reverse) }\end{array}$ & CAACAGCACGCCCCAGTCGA & $20 b p$ & & & & \\
\hline $\begin{array}{l}\text { CURS1 } \\
\text { (forward) }\end{array}$ & CATCATTGACGCCATCGAAGC & $21 b p$ & AB495007.1 & $125 b p$ & 124-125bp & \\
\hline $\begin{array}{l}\text { CURS1 } \\
\text { (reverse) }\end{array}$ & TCAGCTCATCCATCACGAAGTACAC & $25 b p$ & & & & \\
\hline $\begin{array}{l}\text { CURS2 } \\
\text { (forward) }\end{array}$ & TCGGGATCAAGGACTGGAACAAC & $23 b p$ & AB506762.1 & $141 b p$ & $141-142 b p$ & $\begin{array}{l}\text { (Katsuyama } \\
\text { et al. 2009b) }\end{array}$ \\
\hline $\begin{array}{l}\text { CURS2 } \\
\text { (reverse) }\end{array}$ & TGTTGCCGAACTCGGAGAAGAC & $22 b p$ & & & & \\
\hline $\begin{array}{l}\text { CURS3 } \\
\text { (forward) }\end{array}$ & TGGAGCCCTCCTTCGACGACC & $21 b p$ & AB506763.1 & & 95-97bp & \\
\hline $\begin{array}{l}\text { CURS3 } \\
\text { (reverse) }\end{array}$ & CCCATTCCTTGATCGCCTTTTCC & $23 b p$ & & & & \\
\hline $\begin{array}{l}\text { Actin } \\
\text { (forward) }\end{array}$ & GGATATGCTCTTCCTCATGCT & $21 b p$ & $\begin{array}{l}\text { CP002686.1 } \\
\text { AK118354.1 } \\
\text { AY087740.1 }\end{array}$ & $113 b p$ & 115-116bp & $\begin{array}{c}\text { (Chan et al. } \\
\text { 2016) }\end{array}$ \\
\hline $\begin{array}{l}\text { Actin } \\
\text { (reverse) }\end{array}$ & TCTGCTGTGGTGGTGAATGA & $20 b p$ & & & & \\
\hline
\end{tabular}

[details of these primer pairs can be found in NCBI Primer Blast tool specificity check of primers against Curcuma longa cDNA sequences for DCS and CURS(s) genes.]

forward and reverse gene specific primers in $20 \mu \mathrm{L}$ reaction were used under following conditions: one cycle of initial denaturation at $94{ }^{\circ} \mathrm{C}$ for 3 minutes followed by 35 cycles of denaturation at $94{ }^{\circ} \mathrm{C}$ for 30 seconds, annealing at $60{ }^{\circ} \mathrm{C}$ for 30 seconds and extension at $72{ }^{\circ} \mathrm{C}$ for 1 minute, and one cycle of final extension at $72{ }^{\circ} \mathrm{C}$ for 10 minutes. $1.2 \%$ agarose gel electrophoresis showed the specific single band of all primers and no bands were observed in NTC (no template control) and NEC (no reverse transcriptase enzyme control) with some exception of primer dimers of less than 50 bps size in some reactions. This further confirmed the purity and abundant template quantity of cDNA synthesized in the diluted cDNA.

We selected three biological samples (replicates) and two technical samples (replicates) of each turmeric cultivar. Single 96-well plate was set up for all the target genes as well as reference genes. qPCR was carried out in Bio-Rad CFX96 instrument using DyNAmo ${ }^{\mathrm{TM}}$ Flash SYBR ${ }^{\mathrm{TM}}$ Green qPCR Kit (Thermo Scientific, USA) using $0.5 \mathrm{iM}$ of each gene specific forward and reverse primers (Table 1 ) in $20 \mu \mathrm{L}$ final reaction volume. The reaction protocol and plate set up were carried out using Bio-Rad CFX Manager ${ }^{\mathrm{TM}}$ software. The qPCR conditions were as follows: one cycle of initial denaturation at $95{ }^{\circ} \mathrm{C}$ for 7 minutes, followed by 40 cycles of initial denaturation at $95^{\circ} \mathrm{C}$ for 10 seconds, annealing/ extension at $60{ }^{\circ} \mathrm{C}$ for 30 seconds and final melting curve analysis of $65^{\circ} \mathrm{C}$ to $95^{\circ} \mathrm{C}$ was used to check the specificity of the products according to the manufacturer's protocol (Bio-Rad CFX96 Instrument). 


\section{qPCR statistical analysis}

Negative controls were also included to detect any false positives during reverse transcription and qPCR. All the generated data along with $C_{q}$ values were subjected to CFX manager (v.3.1) software package which includes mathematical models for relative quantification, gene expression and normalization of qPCR data as described by Pfaffl (2001) and Vandesompele et al. (2002).

\section{Results and discussion}

Comparative gene expressions in GNT-2 and NDH98

Relative normalized gene expressions were estimated in CFX manager software (Table 2) which described that CURS1 (1.57 fold, $\mathrm{P}=0.17$ ) and CURS2 (1.46 fold, $\mathrm{P}=0.22$ ) had higher fold expression in GNT-2 as compared to NDH98. However, NDH-98 exhibited higher expression of DCS (2.82 fold, $\mathrm{P}=0.07$ ) as compared to GNT-2 (Fig. 1 and Fig. 2). This study at the initial dormancy stage of turmeric rhizome (six months from planting) described the regulated behavior of multiple curcumin synthases viz DCS, CURS1, and CURS2 in turmeric rhizomes of two different cultivars under study. CURS3 expression was almost similar between cultivars.

Gene expression and curcuminoid biosynthesis

NDH-98, a low curcumin cultivar $(1.6 \%$ curcumin), exhibited higher expression of DCS and CURS3 whereas lower expression of CURS1 and CURS2. However, in GNT-2, a high curcumin cultivar ( $4.6 \%$ curcumin), DCS and CURS3 expressions were lower but CURS1 and CURS2 expressions were higher, at six months after planting ( Fig. 1 and Table 3). However, NDH-98 has almost 5 tons/ha higher yield than GNT-2 irrespective of their curcumin content suggesting a significant difference in curcuminoid biosynthesis in rhizomes of two turmeric cultivars. CURS1 and CURS2 expression patterns showed more closer association than DCS and CURS3 gene expression patterns in both the cultivars (Fig. 2). The results indicated that differential gene expression regulation of multiple curcumin synthases occurs in rhizome at this stage of growth. Since gene expression showed tissue specific and time specific variations (Behar et al. 2016), differential gene expression patterns may be observed at different stages of growth. However, in this study, CURS3 expression was almost similar between cultivars describing the significant role of CURS3 in curcuminoid biosynthesis. It was also found that expression levels of the multiple curcumin synthases are capable of curcuminoid synthesis with different substrate specificities which might influence the composition of curcuminoids in the turmeric and in different cultivars (Katsuyama et al. 2009a; Katsuyama et al. 2009b) indicating strong association with curcuminoids. The

Table 2 Gene expression and $\mathrm{C}_{\mathrm{q}}$ for NDH-98 and GNT-2

\begin{tabular}{lccccccc}
\hline Target & $\begin{array}{c}\text { Biological } \\
\text { set }\end{array}$ & $\begin{array}{c}\text { Expression } \\
\text { Actin }\end{array}$ & $\begin{array}{c}\text { Expression } \\
\text { SD }\end{array}$ & $\begin{array}{c}\text { Expression } \\
\text { SEM }\end{array}$ & Mean Cq & Cq SD & Cq SEM \\
Actin & NDH-98 & & & & 26.8064 & 0.8164 & 0.3651 \\
CURS1 & GNT-2 & 1.0000 & 0.9275 & 0.3279 & 29.5452 & 1.0602 & 0.3748 \\
CURS1 & NDH-98 & 0.6363 & 0.479 & 0.1693 & 30.9292 & 0.6895 & 0.2438 \\
CURS2 & GNT-2 & 1.0000 & 1.061 & 0.3537 & 30.8575 & 1.2948 & 0.4316 \\
CURS2 & NDH-98 & 0.6826 & 0.5131 & 0.194 & 32.1401 & 0.6872 & 0.2597 \\
CURS3 & GNT-2 & 1.0000 & 1.1175 & 0.3725 & 29.8096 & 1.3903 & 0.4634 \\
CURS3 & NDH-98 & 1.0678 & 0.7898 & 0.2633 & 30.4468 & 0.6593 & 0.2198 \\
DCS & GNT-2 & 0.5892 & 0.5816 & 0.1939 & 29.4509 & 1.1669 & 0.389 \\
DCS & NDH-98 & 1.6607 & 2.6871 & 1.0156 & 28.6878 & 2.1783 & 0.8233 \\
\hline
\end{tabular}




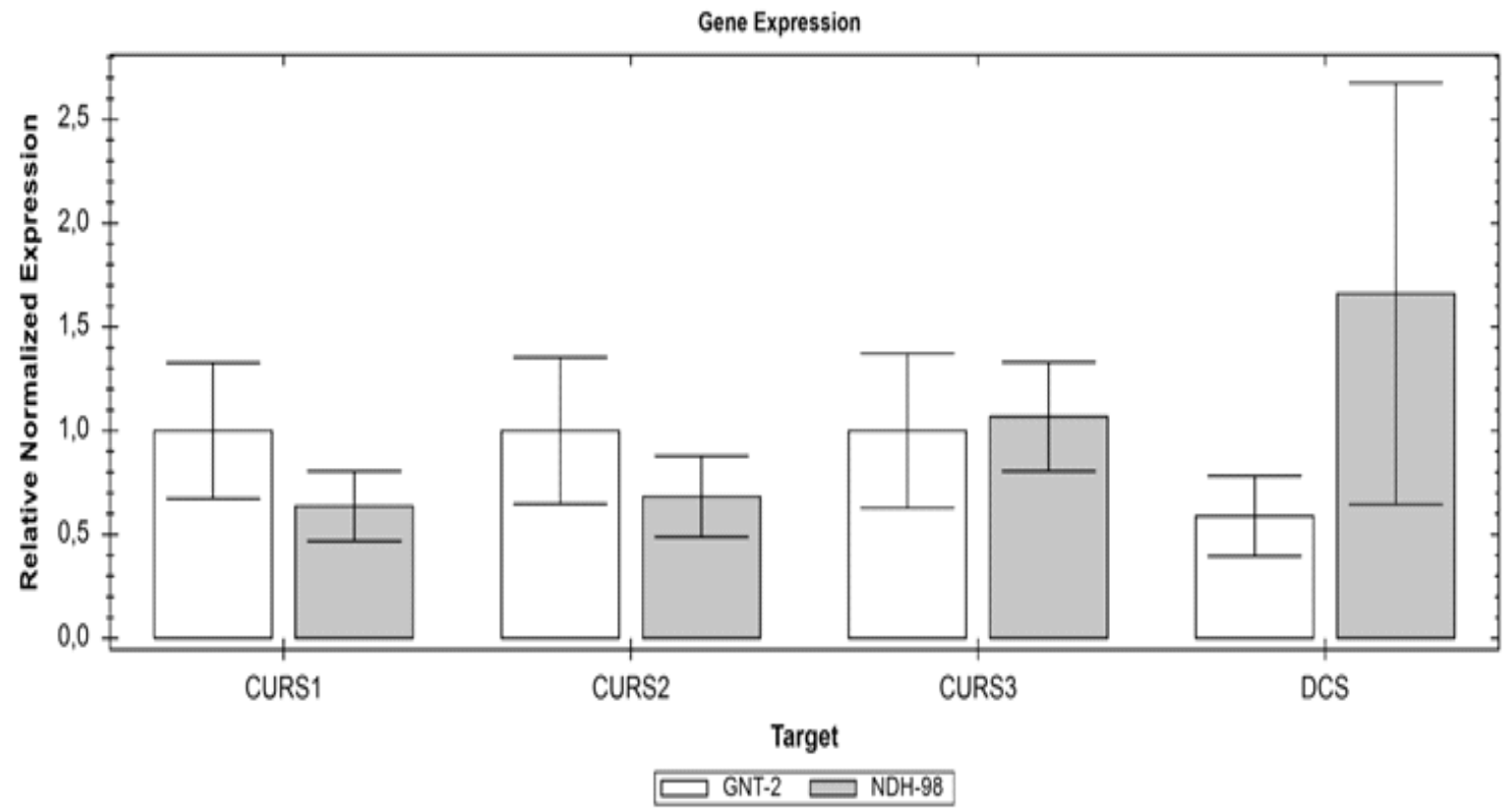

Fig. 1. Relative normalized gene expression between GNT-2 (4.6\% curcumin) and NDH-98 (1.6\% curcumin)

[CURS1 and CURS2 have higher fold expression in GNT-2 as compared to NDH98 whereas DCS depicted higher fold expression in NDH-98 as compared to GNT-2. CURS3 showed similar expression between cultivars.]

expression profiles of CURS1 are closely related to the CURS2 expression profiles whereas that of DCS are closely related with CURS3 expression profiles (Fig. 2). The gene expressions were normalized to the reference gene Actin. Rhizome samples were taken from turmeric cultivars at six months after planting. At this stage of growth, plants were at the final stage of senescence i.e. initial dormancy stage. Based on the metabolic profiling study and gene expression analysis, Li et al. (2015) also reported that the difference in the contents of curcuminoids among

Table 3 Comparative gene regulation between GNT-2 and NDH-98

\begin{tabular}{ccccccccc}
\hline S.N. & Target & $\begin{array}{c}\text { Biological } \\
\text { set }\end{array}$ & Regulation & P-Value & $\begin{array}{c}\text { Exceeds } \\
\text { p-value } \\
\text { threshold }\end{array}$ & $\begin{array}{c}\text { Compared } \\
\text { to regulation } \\
\text { threshold }\end{array}$ & Control \\
\hline 1 & & & & & & \\
2 & Actin & NDH-98 & & 0.9621 & Yes & No change & GNT-2 \\
3 & CURS1 & NDH-98 & -1.5716 & 0.1772 & Yes & No change & GNT-2 \\
4 & CURS2 & NDH-98 & -1.4646 & 0.2252 & Yes & No change & GNT-2 \\
5 & CURS3 & NDH-98 & 1.0678 & 0.5092 & Yes & No change & GNT-2 \\
6 & DCS & NDH-98 & 2.8187 & 0.0761 & Yes & Up regulated & GNT-2 \\
7 & Actin & GNT-2 & & 0.9621 & Yes & No change & NDH-98 \\
8 & CURS1 & GNT-2 & 1.5716 & 0.1772 & Yes & No change & NDH-98 \\
9 & CURS2 & GNT-2 & 1.4646 & 0.2252 & Yes & No change & NDH-98 \\
10 & CURS3 & GNT-2 & -1.0678 & 0.5092 & Yes & No change & NDH-98 \\
\hline & DCS & GNT-2 & -2.8187 & 0.0761 & Yes & Down regulated NDH-98 \\
\hline
\end{tabular}




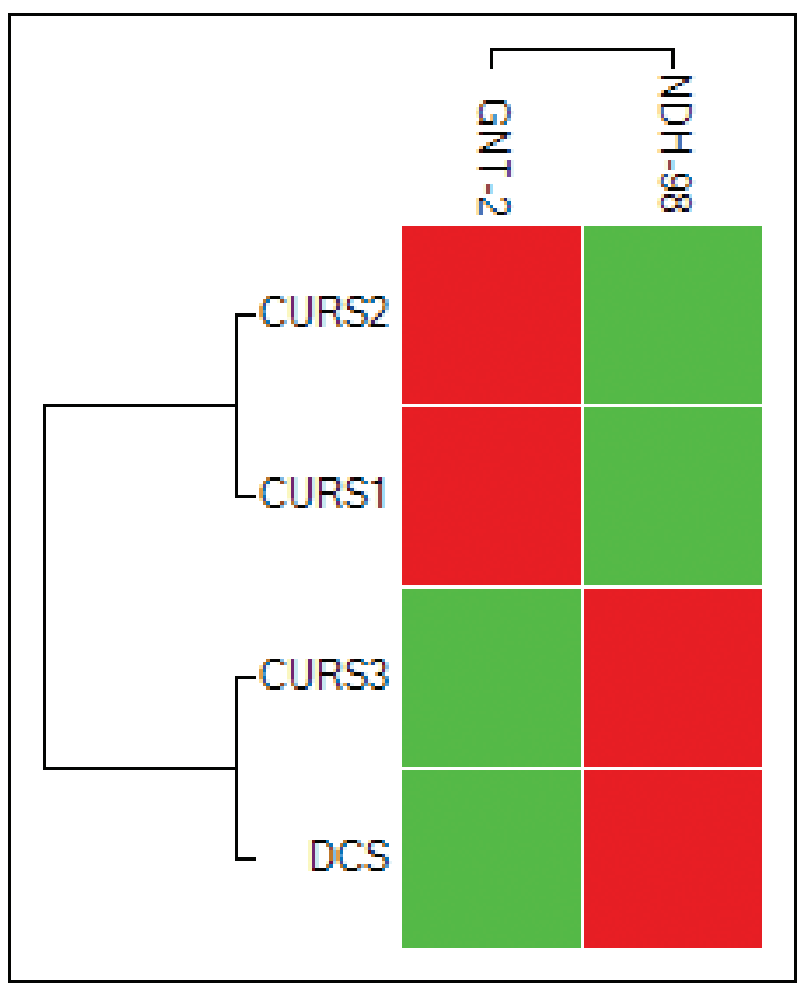

Fig. 2. Cluster diagram showing differential expression of multiple curcumin synthases and association among expression profiles [Dark red colored box represents upregulation of genes whereas green colored box represents downregulation of genes. CURS1 and CURS2 are upregulated whereas DCS and CURS3 are downregulated in GNT-2. However, CURS1 and CURS2 were downregulated whereas DCS and CURS3 genes were upregulated in NDH-98. CURS1 and CURS2 expression pattern showed more closer association than DCS and CURS3 gene expression pattern. For interpretation of the references to colour in this figure legend, the reader is referred to the web version of this article)

the species, as measured by gas chromatography-mass spectrometry, could be explained by the changes in the expression of genes encoding diketide-CoA synthase, and curcumin synthase in curcuminoid biosynthesis pathway. They also reported that higher curcumin containing cultivars showed lower expression of DCS whereas higher expression of CURS1 and CURS2, and vice versa when similar stage of growth was chosen for the study as in this experiment. Expression levels of CURS3 were also found low in four different curcumin containing cultivars as reported by Li et al. (2015) but were similar between leaves and rhizome samples in turmeric (Katsuyama et al. 2009b). The results indicated that differential gene expression profiles of different turmeric cultivars could be predictively associated with different curcuminoid contents of respective cultivars to further elucidate the curcuminoid biosynthesis pathway in medicinally important spice crop, turmeric. Further study in this aspect may explore the association of multiple curcumin synthases gene expressions with curcuminoids synthesis in turmeric.

Two cultivars differing in curcumin content viz GNT-2 (4.6\% curcumin) and NDH-98 (1.6\% curcumin) were taken for comparative gene expression study in association with total curcumin contents. Differential gene expression patterns between two cultivars revealed regulated behaviour of multiple curcumin synthase between two cultivars. NDH-98 exhibited higher expression of DCS and CURS3 whereas lower expression of CURS1 and CURS2. However, in GNT-2, DCS and CURS3 expressions were lower but CURS1 and CURS2 expressions were higher, at six months after planting of rhizome. CURS3 showed similar expressions between two cultivars. CURS1 and CURS2 expression patterns showed more closer association than DCS and CURS3 gene expression patterns with each other. Differential gene expression profiles were observed between two different turmeric cultivars differing in curcumin contents.

\section{Acknowledgments}

We are highly thankful to the Department of Genetics and Plant Breeding, N.M. College of Agriculture, Navsari Agricultural University (NAU), Navsari, India for the funding, laboratory facility as well as genetic material for the study. We are privileged by the excellent coordination and laboratory facility available from Forest Biotechnology Laboratory in ASPEE College of Horticulture and Forestry, NAU, and Sugarcane Research Station, NAU. Suggestions and guidance from Dr. A. V. Narwade, Dr. G. P. Vadodariya, Dr. C. V. Kapadiya, Dr. Madhu Bala, senior scholar Shreya Sen and Haidar Abbas, 
PhD scholar at NAU are acknowledged with appreciation.

\section{References}

Agrawal D K \& Mishra P K 2010 Curcumin and its analogues: potential anticancer agents. Med. Res. Rev. 30: 818-860.

Behar N, Tiwari K \& Jadhav S 2016 Semiquantitative expression studies of genes involved in biosynthesis of curcuminoid in Curcuma caesia Roxb. Indian J. Biotechnol. 15: 491-494.

Chan S N, Abu Bakar N, Mahmood M, Ho C L, Mohamad Dzaki N \& Shaharuddin N A 2016 Identification and expression profiling of a novel Kunitz trypsin inhibitor (KTI) gene from turmeric, Curcuma longa, by real-time quantitative PCR (RT-qPCR). Acta Physiologiae Plantarum 39: 12.

Chan S N, Abu Bakar N, Mahmood M, Ho C L \& Shaharuddin N A 2014 Molecular cloning and characterization of novel phytocystatin gene from turmeric, Curcuma longa. BioMed Res. Int. 2014: 973790.

Esatbeyoglu T, Huebbe P, Ernst I M, Chin D, Wagner A E \& Rimbach G 2012 Curcumin-from molecule to biological function. Angew. Chem. Int. Ed. 51: 5308-5332.

Gupta S C, Sung B, Kim J H, Prasad S, Li S \& Aggarwal B B 2013 Multitargeting by turmeric, the golden spice: From kitchen to clinic. Mol. Nutr. Food Res. 57: 1510-1528.

Katsuyama Y, Kita T, Funa N \& Horinouchi S 2009a Curcuminoid biosynthesis by two type III polyketide synthases in the herb Curcuma longa. J. Biol. Chem. 284: 11160-11170.

Katsuyama Y, Kita T \& Horinouchi S 2009b Identification and characterization of multiple curcumin synthases from the herb Curcuma longa. FEBS Lett. 583: 2799-2803.

Krup V, Prakash L \& Harini A 2013 Pharmacological activities of turmeric (Curcuma longa Linn): a review. J. Homeopathy Ayurv. Med. 2: 133.

Li D, Ono N, Sato T, Sugiura T, Altaf-Ul-Amin M, Ohta D, Suzuki H, Arita M, Tanaka K, Ma Z \&
Kanaya S 2015 Targeted integration of RNASeq and metabolite data to elucidate curcuminoid biosynthesis in four Curcuma species. Plant Cell Physiol. 56: 843-851.

Pfaffl M W 2001 A new mathematical model for relative quantification in real-time RT-PCR. Nucleic Acids Res. 29: e45-e45.

Prasad S \& Aggarwal B B. (2011). Turmeric, the golden spice: from traditional medicine to modern medicine. In I F F Benzie \& S WachtelGalor (Eds.), Herbal Medicine: Biomolecular and Clinical Aspects (2nd ed., pp. 263-282). Boca Raton (FL): CRC Press/Taylor \& Francis LLC.

Ravindran P, Babu K N \& Sivaraman K. (2007). Turmeric. The genus curcuma. Medicinal and Aromatic Plants. Boca Raton (FL): CRC Press/ Taylor \& Francis LLC.

Sandeep I S, Das S, Nasim N, Mishra A, Acharya L, Joshi R K, Nayak S \& Mohanty S 2017 Differential expression of CURS gene during various growth stages, climatic condition and soil nutrients in turmeric (Curcuma longa): Towards site specific cultivation for high curcumin yield. Plant Physiol. Biochem. 118: 348-355.

Sandur S K, Pandey M K, Sung B, Ahn K S, Murakami A, Sethi G, Limtrakul P, Badmaev V \& Aggarwal B B 2007 Curcumin, demethoxycurcumin, bisdemethoxycurcumin, tetrahydrocurcumin and turmerones differentially regulate antiinflammatory and anti-proliferative responses through a ROS-independent mechanism. Carcinogenesis 28: 1765-1773.

Sheeja T E, Deepa K, Santhi R \& Sasikumar B 2015 Comparative transcriptome analysis of two species of Curcuma contrasting in a high-value compound curcumin: Insights into genetic basis and regulation of biosynthesis. Plant Mol. Biol. Rep. 33: 1825-1836.

Vandesompele J, De Preter K, Pattyn F, Poppe B, Van Roy N, De Paepe A \& Speleman F 2002 Accurate normalization of real-time quantitative RT-PCR data by geometric averaging of multiple internal control genes. Genome Biol. 3: Research 0034. 